\title{
Management of recurrent lobular capillary hemangioma of nasal septum
}

\begin{abstract}
Background: Lobular capillary hemangioma $(\mathrm{LCH})$ is a rapidly growing benign lesion characterized by a proliferation of capillaries arranged in lobules, which are separated by a loose connective tissue stroma and infiltration by various inflammatory cells. It is rarely found in the nasal cavity. We present a case of recurrent LCH arising from right side anterior nasal septum in a 31 year old male, highlighting the management strategy to avoid its recurrence.
\end{abstract}

Case report: A 31-year-old man with a recently resected mass in the right nostril 20days prior presented to the OPD with history of intermittent episodes of right sided epistaxis and nasal obstruction for last one month. Diagnostic nasal endoscopy revealed a small reddish lobular mass measuring $1 \times 1 \mathrm{~cm}$ and arising from the anterior nasal septum with attachment in the killians area on the right side. The mass was excised endoscopically under local anesthesia, the septal attachment was stripped of its mucoperichondrium and edges were cauterized Pathology revealed lobular capillary haemangioma. Three months postoperative period has been insignificant.

Discussion: Lobular capillary hemangioma of the nasal cavity commonly presents with recurrent unilateral epistaxis, nasal obstruction, and nasal discharge. Its precise aetiology is unknown although trauma and viral infection have been suggested as etiology. On nasal endoscopy it appears as reddish to purple, with crusted appearance due to associated epistaxis. Only histological examination can establish a definitive diagnosis. Total excision of the lesion is recommended and is best performed by endoscopic surgery techniques.

Conclusion: Proper technique of appropriately removing a lobular capillary haemangioma and decreasing the risk of recurrence involves stripping the mucoperichondrium from its attachment with cauterization of the base.
Volume 10 Issue 4 - 2018

\section{Nitin Arora, Jyoti Singh, Suchina Parmar, Jai Lal Davessar}

BFUHS, GGS Medical College and Hospital, India

Correspondence: Nitin Arora, Senior Resident (ENT), BFUHS, GGS Medical College and Hospital, Faridkot, India, Tel 9815260243, Email drnitinarora89@gmail.com

Received: May 25, 2018 | Published: August 06, 2018

Keywords: hemangioma, nasal septum, nasal obstruction, LCH, lobular capillary hemangioma

\section{Background}

Lobular capillary hemangioma (LCH) is a rapidly growing benign lesion, characterized by a proliferation of capillaries arranged in lobules, separated by a loose connective tissue stroma, with infiltration by various inflammatory cells. ${ }^{1}$ Skin and mucous membranes of the oral cavity has been reported to be a common site of origin of $\mathrm{LCH}$, while it is rarely found in the nasal cavity. ${ }^{2}$ Its precise etiology is not known although trauma and viral infection have been suggested to be etiological factors. ${ }^{3}$ It presents with recurrent epistaxis and nasal obstruction. We present a case of recurrent $\mathrm{LCH}$ arising from right side anterior nasal septum in a 31year old male, highlighting appropriate the management strategies to avoid its recurrence.

\section{Case report}

A 31-year-old man with history of a mass in the right nostril status post resection 2 months prior presented to the OPD complaining of intermittent episodes of right sided epistaxis and nasal obstruction for last one month. The bleeding episodes tend to resolve spontaneously after $4-5$ minutes. The patient states that the mass recurred approximately 1 month after the resection. At the time of resection, no histopathological examination was performed. On further inquiry, the patient revealed minor trauma in the right nostril from a nose hair trim approximately 3 months prior. Diagnostic nasal endoscopy revealed a lobular mass of $1 \times 1 \mathrm{~cm}$ arising from the anterior nasal septum with attachment in the killians area on the right side. It was reddish, pedunculated and crusted due to recurrent epistaxis (Figure 1)

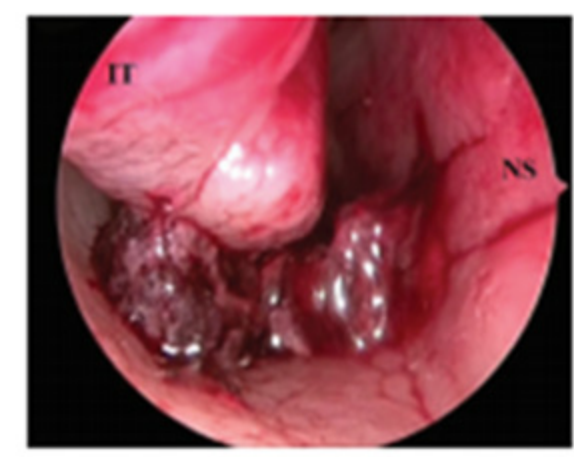

Figure I Diagnostic nasal endoscopy showing a lobular growth arising from the inferior turbinate.

The other local and systemic examinations were unremarkable. CT PNS was performed and revealed a soft tissue density arising from the nasal septum without any involvement of the sinuses. The mass was excised endoscopically under local anesthesia A rolled gauge soaked in a solution of $4 \%$ xylocaine with one ampule of adrenaline was placed all around the mass. The anterior septum area around the attachment of the mass was then injected with $2 \%$ xylocaine 
with adrenaline.

The mass was removed using a straight blakeselly forceps and the mucoperichondrium was stripped off from the area of attachment, exposing the underlying cartilage. The edges of the created wound were then cauterized using unipolar cautery (Figure 2). Packs were removed the following day. Histopathology examination revealed lobular capillary haemangioma (Figure 3). Three months postoperative period has been insignificant.

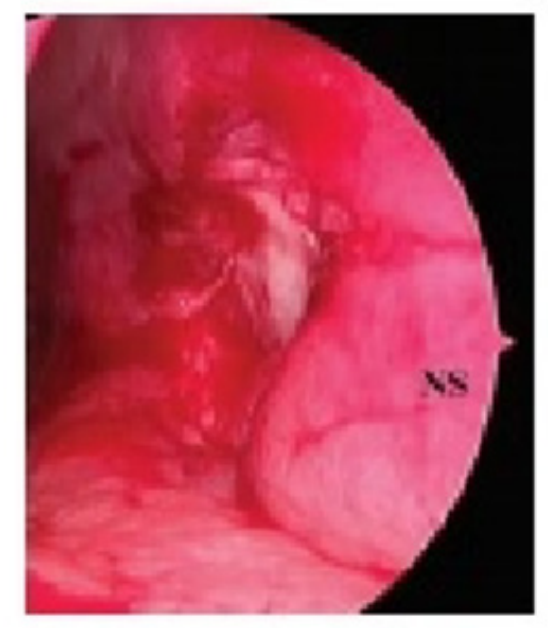

Figure $\mathbf{2}$ The nostril was then packed.

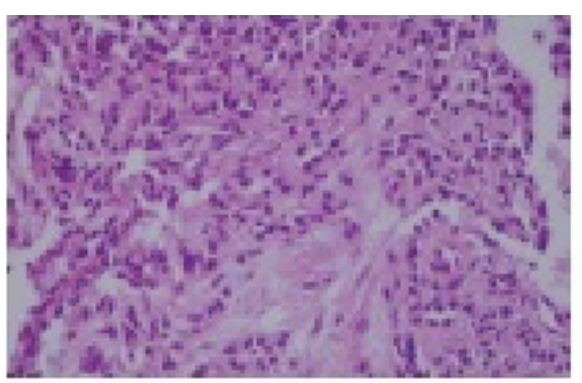

Figure 3 Lobular capillary haemangioma.

\section{Discussion}

Lobular capillary hemangioma is a rapidly growing benign lesion, characterized by a proliferation of capillaries arranged in lobules and separated by a loose connective tissue stroma, with infiltration by various inflammatory cells. The most common sites of mucosal LCH is oral mucosa. Nasal cavity involvement is uncommon, though when they do occur; with the most common sites of occurrence are the anterior septum and inferior turbinate. ${ }^{4}$

Recurrence can be avoided if we strip the underlyng mucoperichondrium and expose the cartilage. ${ }^{2}$ Other methods of treatment are using chemical cautery in place of electric cautery, but electric cauterisation is preffered method. Lobular capillary hemangioma arising from the nasal cavity commonly presents with recurrent unilateral epistaxis, nasal obstruction, and nasal discharge. ${ }^{5}$

$\mathrm{LCH}$ is most commonly seen in the third and fifth decades of life. ${ }^{6}$ Its precise aetiology is not known although trauma and viral infection have been suggested to be etiological factors. In our patient, the lesion may have risen from the minor trauma he had reported from a nose hair trim. On nasal endoscopy, these lesionsappear as a reddish to purple mass with a crusted appearance due to associated epistaxis. Usually it is around $1 \mathrm{~cm}$ in size; however the lesion may rarely reaches a considerable size, filling the nasal cavity entirely. On CT scan imaging, the lesion appears as intense enhancing, bony changes are very rare. ${ }^{7}$ On MRI, it shows T2 hyperintensity and T1 isointensity that avidly enhances with contrast administration. ${ }^{8}$ However, the imaging appearance is nonspecific. Only histological examination can establish a definitive diagnosis. Histopathologically $\mathrm{LCH}$ has extensive endothelial proliferation with prominent vascular spaces, lobular arrangement of capillaries with ulcerated epithelium and has a base that is made up of fibrovascular tissue. Occasionally mixed inflammatory infilterate is can also be seen. ${ }^{9}$ Total excision of the lesion is recommended and is best done by endoscopic surgery techniques. ${ }^{10}$ Recurrence is not common if surgical excision is done properly. ${ }^{11}$ Management strategy is discussed in our case report.

\section{Conclusion}

$\mathrm{LCH}$ is rarely seen lesion in the nasal cavities. Although the exact etiology is not clear, local trauma in the region of anterior nasal septum is considered to be a significant etiological factor in our case report. Proper technique of excising the mass includes stripping the mucoperichondrium from attachment if arising from septum with cauterization of the base is considered ideal treatment so as to prevent the recurrence. Recurrence can be avoided if we strip the underlyng mucoperichondrium and expose the cartilage. Other methods of treatment are using chemical cautery in place of electric cautery, but electric cauterisation is preffered method.

\section{Acknowledgements \\ None.}

\section{Conflict of interest}

The author declares no conflict of interest.

\section{References}

1. Nicolai P, Castlenuove P. Benign tumours of sinunasal tracts ; cummings otolarygology head and neck surgery. Philadelphia. 2010;5:725.

2. Ozcan C, Apa DD, Görür K. Pediatric lobular capillary hemangioma of the nasal cavity. Eur Arch Otorhinolaryngol. 2004;261(8):449-451.

3. O connel M. Conditions of external nose;Scott Brown otorhinolarygology head and neck surgery. Greater Britain. 2008;7:1708.

4. Akyol MU, Yalciner EG, Doğan AI AI. Pyogenic granuloma (lobular capillary hemangioma) of the tongue. Int J Pediatr Otorhinolaryngol. 2001;58(3):239-241.

5. Puxeddu R, Berlucchi M, Ledda GP, et al. Lobular capillary hemangioma of the nasal cavity: a retrospective study on 40 patients. Am J Rhinol. 2006;20(4):480-484.

6. Ifeacho SN, Caulfield HM. A rare cause of paediatric epistaxis: lobular capillary haemangioma of the nasal cavity. BMJ Case Rep. 2011;2011:pii: bcr0720103199. 